\title{
The Beijing Independent Film Festival: Translating the Non-Profit Model into China
}

\section{Flora Lichaa}

\section{Introduction}

This essay focuses on the Beijing Independent Film Festival (BIFF). It considers the problem of translating a particular foreign model of film festivals - the "festival-as-nonprofit"-into the contemporary People's Republic of China (PRC). This model relies on the existence of a social and material space free from government oversight: the existence of such space in China is, at best, contested. In consequence, independent film festivals seeking to develop the "not-for-profit" model in the PRC have had to adapt it in the face of continued government interference. Here, I use BIFF as a case study through which to trace this process of translation. Though ultimately unsuccessful, precisely because of the tightening of central control over grassroots events of all kinds, I argue that for a period BIFF existed as a variety of "third space," challenging the traditional dualisms on which Chinese society is often built. This suggests that the success of western film festival models in the PRC depends on the extent to which they are perceived to directly challenge government authority.

\section{Chinese Independent Film Festivals and the Problem of Translation}

Since the late 1990s, the advent of digital technologies in China has permitted the rise of amateur filmmaking. These films were made individually or in small teams with digital cameras, outside the Chinese film industry and the government censorship system. They were thus defined as "independent" (duli or minjian) and could not be screened in China on television channels, in film theaters, or at those festivals that mainly showed big budget films, tightly controlled by the State Administration of Press, Publication, Radio, Film and Television (SAPPRFT). In order to address this lack of visibility, independent filmmakers and film critics worked together first to create film clubs-informal gatherings where people watched an discussed independent cinema that were held in venues ranging from homes and coffee houses to university classrooms - and soon afterward independent festivals in China's major cities throughout the 2000s.

The evolution from film clubs to festivals reflects the organizers' desire to escape the 
cramped conditions of cafes, and to enhance the profile of these events, attracting the attention of a wider audience. In 2001, the first Chinese independent film festival, the First

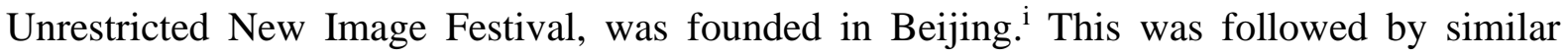
events in other cities. According to Ying Liang, director and founder of the Chongqing Independent Film and Video Festival (CIFVF), these festivals were largely modeled on the only obvious paradigm: film festivals abroad. ${ }^{\text {ii }}$ From the early 1980 s on, foreign festivals were the only way to see Chinese "avant-garde" films banned in China; directors such as Zhang Yimou, Chen Kaige, Lou Ye, and Jia Zhangke, amongst others, were regularly invited to festivals such as Cannes, Berlin, and Venice. At the end of the 1990s, Chinese independent films were selected to screen at smaller-scale festivals such as the Yamagata International Documentary Film Festival (YIDFF), Cinéma du Réel, International Film Festival Rotterdam (IFFR), Jeonju International Film Festival (JIFF), Black Movie, and Visions du Réel. Setting up film festivals was therefore a way for Chinese independent cinema to seek the recognition of the global film community.

The type of festival Chinese independent filmmakers have tried to import is perhaps best characterized as the "festival-as-non-profit." This is defined by Ragan Rhyne as a new model of cultural administration that spread globally following the end of the Cold War. Rhyne argues that most films festivals have now adopted this institutional structure, thus becoming part of a "global cultural industry" or "global third sector." various organizational configurations that fall under the "festival-as-non-profit" model include small and medium-sized events that specialize in a particular geographical or cultural focus (for example, Vietnamese or Kurdish cinema), specific genres (ethnographic or experimental), or cinema by or about specific social groups (women, LGBTQ, children). These specialist events, often called community-based film festivals, aim to reflect the values, interests, and aspirations of a particular community. ${ }^{\text {iv }}$ They can also be considered "corrective festivals," the term proposed by Dina Iordanova in her chapter in this volume for events that seek to "correct" dominant discourse on a sociopolitical topic by programming alternative narratives around this issue. In line with this model, Chinese independent film festivals try to promote plural understandings of Chinese society through screenings and discussion. As community-based festivals, they present very few commercial opportunities, relying on private networks for funding and venues, and on volunteers for their organization. The main point of departure from the western community-based festival model lies in the difficulty of programming films in publicly accessible locations without authorization from 
the government.

This difference between western and Chinese film festivals creates problems of translation. While Chinese film festivals always include the term "festival" in their English names, they are designated by several names in the Chinese language, depending on their legal status. The officially recognized events, referred to as dianyingjie (film festivals), must be registered with the administration and submit their programs for state censorship. Independent film festivals cannot use the Chinese term dianyingjie as they are not officially registered. ${ }^{\mathrm{v}}$ This is why their Chinese names varies from jiaoliuzhou (exchange week) to yingzhan (film exhibition). BIFF's Chinese name was initially Beijing duli dianyingzhan (Beijing Independent Film Exhibition). After BIFF was amalgamated with the China Documentary Film Festival (CDFF) in 2012, as discussed later in this chapter, its Chinese name was changed to Beijing duli yingxiangzhan (Beijing Independent Image Exhibition).

These translation problems suggest that, despite the importation of a foreign model and of an English name, the shape and nature of a Chinese event will necessarily be different. Walter Benjamin describes this inevitable gap between the original and the translation in his essay "The Task of the Translator":

No translation would be possible if in its ultimate essence it strove for likeness to the original. For in its afterlife-which could not be called that if it were not a transformation and a renewal of something livingthe original undergoes a change. Even words with fixed meaning can undergo a maturing process. ${ }^{\mathrm{vi}}$

My analysis of BIFF attempts to understand how this process of transformation has taken place in relation to Chinese independent film festivals. During my doctoral research, which focused on Chinese independent documentary filmmaking, I regularly participated in Chinese independent festivals in order to stay up-to-date with the latest film releases, as well as meet the filmmakers and the main stakeholders involved in film production, distribution, and criticism. From 2010 to 2013, I conducted around 40 interviews, carried out participant observation during the festivals, and gathered films and written documents produced by the independent film community. For this chapter, the case of BIFF seemed to me particularly interesting, since the festival is characterized by the tenacity of its organizers and their ability to adapt to government restrictions. During the process of negotiation between the festival and the authorities, ${ }^{\text {vii }}$ BIFF's organizers had to reduce the size of the event, moving from 
publicly accessible places to the private space of their offices. As the state increased its interference in this private physical space, the festival's organizers engaged in a fight to protect it.

The process of translation involved in the case of BIFF therefore involves notions of public space, publicly and privately owned spaces that are accessible to the general populace, and private space, personal places not accessible to the general public. ${ }^{\text {viii }}$ The festival could not continue to hold screenings in publicly accessible places since these are directly related to the wider social and political community. In western academic research, this idea of a "political public space" is often used in reference to Jürgen Habermas' analysis of the creation of a bourgeois public sphere in I at the beginning of the eighteenth century. Opinions expressed in this public sphere play the role of mediator between the needs of society and the state. ${ }^{\text {ix }}$ This political public space is usually considered a prerequisite for the emergence of civil society in democratic polities. However, in China, the existence of such a buffer zone remains a subject of debate. Some scholars consider the development of semiautonomous organizations a sign of the emergence of civil society, while others adopt a corporatist approach, emphasizing the government's control of any form of association. ${ }^{\mathrm{x}}$ This debate notwithstanding, recent studies of contemporary Chinese society note that public space, both physical and political, remains subject to strict control by the party-state. In the case of BIFF, even the private physical space of their offices-which I consider to be an individual space unrelated to public affairs in democratic polities - was placed under close surveillance by the Chinese authorities. This chapter thus reflects on the sociopolitical meaning of the private space into which BIFF withdrew, arguing that it developed as a hybrid and transgressive space that contributed to the questioning and redefining of certain dualist categoriesgovernment-independent, public-private, and national-transnational - that help shape Chinese society.

\section{The Foundation and Transformation of BIFF}

BIFF was founded in 2006 in Songzhuang, an artists' village located east of Beijing on the border of Hebei Province. It was established by Li Xianting, a contemporary art critic and curator, and Zhu Rikun, the founder of Fanhall Studio, a non-profit organization working to promote Chinese independent film. In order to finance the event, Li Xianting sought the support of artists such as Fang Lijun and Zeng Fangzhi and created an eponymous foundation 
to raise funds ${ }^{x i}$ Fanhall Studio and the Li Xianting Foundation then worked together to set up two annual festivals, CDFF, created in 2004 by Zhu Rikun, and BIFF. Zhu Rikun was responsible for the film programming and the organization, while Li Xianting sought out new funding sources and managed relationships with the local authorities.

Initially, screenings took place in the auditorium of Songzhuang's Museum of Contemporary Art, of which Li Xianting had recently been appointed director, and in Fanhall Studio's private and non-commercial film theater. In an August 2012 interview, Li Xianting explained that the first two festivals took place without any problems. From 2008, however, the authorities began to check the festival's film selection in advance and to request the withdrawal of those titles considered too "sensitive." Faced with BIFF's refusal to cooperate, the authorities sent repeated warnings to the organizers. ${ }^{x i}$ This pressure led to the cancellation of a screening of Xu Xin's Karamay in the spring of 2010. This documentary captures the testimony of parents who, in 1994, lost their children in a community hall fire in a city in Xinjiang Province; the parents blamed local officials for the disaster. The authorities threatened Zhu Rikun with reprisals if the film was shown during the festival, resulting in the screening's cancellation, and a formal apology from Zhu to the filmmakers at BIFF's closing ceremony.

In spring 2011, an art exhibition was launched in Songzhuang in support of the "jasmine" protests that spread through China's major cities following the Arab Spring. The artists' village was placed under close surveillance and CDFF was canceled. Weary of the constant pressure he had been under for months, Zhu Rikun announced his withdrawal from the organization of the two festivals. Wang Hongwei, a friend of Zhu Rikun best known for playing the lead role in Jia Zhangke's first feature film, Xiao Wu, took over the management of Fanhall Studio. Zhang Qi, the wife of an artist newly settled in Songzhuang, met Li Xianting and took the lead in coordinating the activities of the foundation. ${ }^{x i i}$ During this restructuring, the authorities forbade $\mathrm{Li}$ and Zhang from using the Songzhuang museum for the festival and placed Fanhall Studio's private cinema under close surveillance. Fanhall Studio's website was also blocked. Determined to hold the screenings, the team reorganized the offices of the foundation and installed the necessary projection equipment. During negotiations with Songzhuang government officials, Li Xianting argued that the local government could not prevent him from organizing screenings in the privacy of his own home. The sixth edition of BIFF thus went ahead, despite an opening ceremony interrupted 
by the authorities. ${ }^{\text {xiv }}$

Faced with these difficulties, and the likely intensification of pressure in the run up to the eighteenth Chinese Communist Party National Congress in November 2012, ${ }^{\mathrm{xv}}$ the organizing team decided to amalgamate the two festivals into a common event under the BIFF banner. Two editions of the joint festival followed, in 2012 and 2013; both were held in the courtyard of the Li Xianting Foundation, and both were partially canceled. Some screenings were held at the foundation; the rest of the time, the few remaining participants had to watch films either on the foundation's computers or on DVD copies provided by the organizing team. In 2012, small private screenings were also organized in some artists' studios in Songzhuang. Finally, the 2014 edition was completely shut down by the authorities, who prohibited access to the foundation and confiscated its film archive.

\section{From Public to Private Space}

This overview shows how political restrictions have led to changes within the festival organizing team and forced BIFF to reduce its size and visibility. Based on the above, one might wonder the significance of a festival that cannot take place in publicly accessible venues. To address this question, we need to consider the purposes served by other Chinese independent film festivals. First, these events provide Chinese independent films with a domestic exhibition platform, giving young urban audiences the chance to see this cinema. Second, they are an opportunity for these films to be selected for foreign festivals, since some events are attended by overseas programmers. Independent film festivals in China are therefore part of what Dina Iordanova calls the "business of showing films," as distinct from the "business of film distribution." This distinction reflects the benefits directors derive from the festival circuit: it helps enhance their international recognition as a form of symbolic capital, but offers little in the way of commercial gain, other than the possibility of obtaining funding for the production of forthcoming projects. ${ }^{\mathrm{xvi}}$ Last, but not least, Chinese independent festivals function as spaces for community building, enabling filmmakers, film critics, and programmers to gather together and meet over the course of the year at the various different festivals.

However, since 2008, increasing government interference has led to the social and spatial marginalization of independent cinema in China. Attempts to hold festivals in 
locations accessible to the public have been largely abandoned. Some events, like the Yunnan Multiculture Visual Festival (Yunfest) in Kunming, Yunnan Province, have tried to find new venues in which to hold private screenings. This strategy worked for Yunfest in 2007, but could not be repeated in 2013, due to threats made by the authorities to the festival organizers. The intermediary role these festivals play between the Chinese independent film scene and overseas festivals has continued with some difficulty: only programmers who speak Chinese and enjoy the confidence of organizers and filmmakers can attend and receive DVDs of the films programmed. Community building, while possible on a small scale, has largely been dependent on the mindset and resources of the organizers. Most of the independent festivals have reacted as follows: after announcing the official cancellation of the event, the organizers and those participants still present meet informally, in cafes or at a central venue, to watch DVDs and discuss the festival's situation.

Against this backdrop, BIFF's distinctiveness can be summarized in two ways. First, the festival took place every year until 2014, in a reduced configuration, holding screenings in the foundation as well as in artists' studios. These screenings were possible because BIFF's organizers had their own private spaces and were not dependent on public institutions or private venues subject to the rules of commercial and government censorship. This was not the case with the other festivals: the China Independent Film Festival (CIFF) in Nanjing occurred primarily at Nanjing University; Yunfest was held in Yunnan Provincial Library and at the Yunnan University in Kunming; while CIFVF took place at Chongqing University and in commercial film theaters round the city. Zhu Rikun thus claimed independence from government institutions and commercial cinemas, stating that this was one of the major differences between BIFF and other independent festivals. However, this independence was not entirely the choice of the festival organizers. Li Xianting explained that Zhang Yaxuan, a film critic and founder of the China Independent Film Archive (CIFA), originally wanted CDFF to be organized in collaboration with the Beijing Film Academy (BFA). However, Li maintained that since political controls in Beijing are more stringent than in other Chinese cities, collaboration of this sort was impossible. ${ }^{x v i i}$ Whatever the reasons behind this decision, it paved the way for BIFF to screen films in private spaces, despite the authorities' prohibition on holding screenings in Songzhuang's Museum of Contemporary Art.

Second, BIFF has always attached importance to gatherings of filmmakers and participants both during and outside the festival proper. This is partly due to Zhu Rikun's 
willingness to support independent filmmakers by providing them with space for regular meetings, both at the Li Xianting Foundation where the organizing team had its offices, and at the Fanhall Studio where regular screenings were held. ${ }^{\text {xiii }}$ Directors gathered at these two places throughout the year to share their filmmaking experience and receive peer feedback on their latest work. Some lived in Songzhuang, paying lower rents than in the capital proper while remaining close to the foundation; others visited every time they were in Beijing. Students, researchers, programmers, and journalists interested in Chinese independent cinema also came to meet the organizing team and watch films on the foundation's computers. In addition to these regular meetings the two festivals punctuated the year, offering directors the opportunity to show the fruits of their labor to a wider audience, and to see the best films rewarded. Consequently, while other independent festivals have place more emphasis on the role of public diffusion rather than on community building, CDFF and BIFF have always attached equal importance to these complementary functions: the "event" function, with its temporary time frame, aimed to facilitate encounters between the films and their audience, while the "living space" function embodied the temporality of daily practice for the independent filmmakers.

The latter function meant that, despite the forced retreat from publicly accessible places, BIFF still had a core reason to continue. It thus carried on performing this function in private spaces belonging to the organizers and to artists supporting the festival. One could argue that the number of people who regularly gathered at the foundation was insignificant, and that such events were little more than friends socializing. I believe, however, that the creation of such a space is important in the Chinese context, because it opened up new possibilities for social interaction. BIFF's organizers encouraged the gathering of filmmakers who shared common values and experiences, enabling them to find comfort in a community where they felt understood. The foundation thus became a place where new identities could be forged and individuals could reinvent themselves outside the traditional Chinese social ties of family, clan, ancestral village or city, and place of employment. ${ }^{\text {xix }}$ I would therefore argue that BIFF, as with all Chinese independent film festivals, was at the heart of a process of deterritorialization through which individuals were uprooted from a single geographical and temporal space and dispersed to new "places of anchorage." I surmise that the authorities adopted a more aggressive attitude toward the festival in 2014 because the Li Xianting Foundation had by this point become a significant symbolic place of anchorage for the Chinese independent film sphere. The confiscation of the film archive can thus be interpreted 
as reflecting the desire of the authorities to put a stop to BIFF not only as a festival, but also as a place for community building. However, this is only an assumption, since it is difficult to understand the government's intentions.

\section{The Politicization of BIFF: From Elitism to Public Resistance}

If BIFF's multiple functions and access to private space enabled it to forge ahead in the face of pressure from the state, I would also argue that the resulting organizational changes and the progressive marginalization of the festival encouraged both its organizers and independent filmmakers to assert their opposition to the Chinese government's policies. This does not mean that BIFF was originally detached from politics: the organizers of the other Chinese independent film festivals and the filmmakers have always considered BIFF to be more radical than its counterparts. However, Zhu Rikun and Li Xianting did not share a common understanding of the festival's independence.

Zhu Rikun insisted on complete independence for the festival's programming and editorial line, refusing any form of self-censorship. He defended both politically sensitive documentaries and experimental videos, and did not hesitate to screen four to five hour-long films. He thus demonstrated a desire to carry out his goals without any concessions to the Chinese authorities, while also placing little importance on the views of the festival audience. ${ }^{\mathrm{xx}}$ His attitude was similar to that observed by Howard Becker in his analysis of the behavior of jazz musicians: the fear of having to sacrifice artistic standards rendered the musicians hostile to their listeners. The result was a tendency toward self-segregation that appeared in both the musicians' work and in their relations with the outside community. The musicians created physical and symbolic barriers in order to protect themselves from their audience. These symbolic barriers included common linguistic conventions, in particular the use of jargon or specific references unknown to people outside their community. ${ }^{\mathrm{xxi}}$ In effect, Zhu Rikun also adopted an elitist attitude to protect the film standards he espoused. I therefore conclude that the spatial and social isolation during the first years after the establishment of the two festivals was not only linked to political limitations but also to a genuine desire on the part of the management team to preserve the spirit of the avant-garde. From 2008, in response to BIFF's increasing marginalization by the authorities, Zhu refused to consent to this treatment, retreating voluntarily within the walls of his community, and finally withdrawing altogether. 
On his part, Li Xianting advocated a vision of independence that targeted the Chinese authoritarian regime. For him, Chinese independent film festivals were both a means of supporting independent filmmaking and a way of developing exchanges among intellectuals, following the civil society model. As stated in the introduction to the festival catalogue for the 2012 festival, he wanted to create links between independent filmmakers and other small communities:

What I call "small environments" has to do with "small circles", but the two are not the same. For example, the milieu of independent filmmakers is, naturally, a "small circle," but if this "small circle," in the process of interacting with society, can form an unofficial community based on common values, then it becomes what I call a "small environment". . . At a time when the whole of mainstream culture is tending toward consumerism and entertainment, at a time when we can neither change the wider environment with anger, nor fully express our anger, I believe what we can do for our culture is to promote the formation of unofficial "small environments" in all social arenas. This is a constructive effort; it builds culture from the bottom up. ${ }^{\text {xii }}$

Li believed that the best way to contribute to the formation of these small environments was to be flexible and try to deal with difficulties strategically. ${ }^{x x i i}$ Zhu Rikun's departure should therefore have allowed BIFF to engage with a wider audience. However, only a relaxation of government control over the third sector would truly have allowed independent filmmakers to shed their elitism and interact with the rest of society. Instead, BIFF's organizers had to unite in the face of adversity and focus all their energy on the survival on the festival. Li Xianting explained in this respect that though he had wanted to study Chinese independent films since the creation of his foundation, he had not had time to do so, since he was faced with the need to focus on negotiations with officials. ${ }^{x x i v}$ Therefore, the intensification of political pressures and the departure of Zhu Rikun, who was the most involved in programming work, had an important consequence for the festival: resistance to the government's restrictions began to take precedence over curatorial policy.

This evolution can be observed in the catalogues of successive editions of the two festivals. In his editorial for the fourth BIFF in 2009, Zhu Rikun affirmed the importance of the festival's existence, but remained unclear about the direction in which he wished to guide the event:

Since the founding of the BIFF in 2006 up to now, we are still in the process of exploring the style and direction of our film festival. These 
questions must still be confronted in future years as we maintain a certain kind of unfixed position, or perhaps a kind of valuable wariness. ${ }^{\mathrm{xxv}}$

In the editorial for the fifth BIFF, he set out the two major tasks that a festival faces: "Film festivals need to resolve two problems: first, the selection of the type of films, and second, how to show these films." ${ }^{x x v i} \mathrm{He}$ went on to explain his programming choices. But in the editorial for the sixth festival in 2011, after Zhu Rikun's withdrawal, we note that the tone has changed. Li Xianting declared his determination to support independent cinema despite the current difficulties:

In May 2011, the eighth China Documentary Week directed by Zhu Rikun was forced into cancellation. This October 2011, the sixth Beijing Independent Film festival directed by Wang Hongwei has been forced to move and yet officials want to call Songzhuang China's largest community for contemporary artists. With this kind of regrettable situation wherein the various places for film exhibition meet with so many interferences from officials, the future progress of independent cinema remains under duress ... Supporting independent cinema and providing it with a better exhibition platform is the kind of work that our foundation and all of those who love independent cinema are glad to do . .. At the same time, for those involved in independent cinema, we must be even more devoted to our work, and face the upcoming challenges with a firm and peaceful mind. .xvii $^{\text {xir }}$

This sentiment of determination was repeated in the editorial for the following year, and was illustrated on the cover of the catalogue, which featured the image of someone trying to ride a unicycle on a tightrope. Finally, the introduction to the festival catalogue for the 2013 edition focused entirely on the festival's difficulties and ended with a quote from Cui Weiping, a former professor at the BFA: "we must keep going no matter if we are alive or not!"xxviii The message was clear: the organizing team was determined to continue the festival at all costs.

To clarify this transition from a commitment to support independent cinema to political activism, a parallel can be drawn with the forms of political resistance described by Václav Havel during the decade following the 1968 invasion of Czechoslovakia. Havel observes that individuals who refused to accept the restrictions imposed by the authorities were labeled "dissenters," although they did not initially decide to engage in dissenting activities:

You are thrown into it by your personal sense of responsibility, combined with a complex set of external circumstances. You are cast out of the existing structures and placed in a position of conflict with them. 
It begins as an attempt to do your work well, and ends being branded an enemy of society. ${ }^{\text {xxix }}$

This suggests that what academic publications and media reports usually call "political activism" or "political dissent" is in this context less the result of a pro-active decision on the part of the "activists" and more a defensive reaction by said "activists" to government activity. This phenomenon has also been observed in the Chinese context. In his book Defending Rights in Contemporary China, Jonathan Benney points out that the distinction between moderate and radical activist lawyers

is not so much in the strategies they pursue, or in the way they interpret law, but rather in how the state responds to them. Hence the labels attributed to a particular lawyer might change while their work stays the same. $^{\mathrm{xxx}}$

Benney further explains that the authorities can suddenly suppress the activities of lawyers as a response to current events or new government policies. In other words, moderate lawyers are considered radical as soon as the government changes its attitude toward their activities. Václav Havel argues that this self-defensive reaction can sometimes be followed by individual or collective actions that involve direct conflict with the authorities. These actions are driven by a new sense of responsibility, which can be defined as the awareness to engage in a collective refusal to comply with government policies. $^{\text {xxxi }}$

In a similar manner, the English-language media coverage began to portray BIFF as a site of political advocacy after the authorities asked Zhu Rikun to cancel the screening of the documentary Karamay. Li Xianting then started to develop survival strategies for the festival, asserting publicly his commitment to the preservation of the Chinese independent film sphere despite government restrictions. During and after the 2012 to 2014 editions of the festival, the organizers, filmmakers and members of the audience gave interviews to the media, mainly describing police intervention in the face of the determination of the organizers and directors. It is noteworthy that this political battle was often placed in the context of the struggle for civil rights, as this comment by David Bandurski, editor of the Hong Kong-based China Media Project website and the producer of several Chinese independent films, demonstrates:

It's not just about films, it's about activism, it's about being tied in and participating in social issues and using film as a medium to explore those, so that's what they [the Chinese authorities] are really interested in nipping in the bud. ${ }^{\text {xxxii }}$ 
This image of political activism was the one that has spread beyond the actual event, reaching a wider audience through what Daniel Dayan calls "the written festival" - the multiple representations of a film festival that emerge through its journalistic coverage. ${ }^{\text {xxiii }}$ On the one hand, this coverage enabled BIFF's key stakeholders to extend their influence beyond the confines of the Li Xianting Foundation, and to publicize their case to the outside world. On the other hand, it gave readers the impression that independent cinema was mostly concerned with the fight for Chinese democracy, while ignoring issues related to the aesthetic qualities of the films produced.

\section{BIFF as Third Space: Hybridity, Transgression, Translation}

This analysis demonstrates that BIFF's transformation had significant sociopolitical implications. To understand the nature of these implications, I propose to look at the bigger picture. As noted at the beginning of this essay, the founder-organizers of China's independent film festivals were both inspired by the first Chinese independent film festivals and by the global model of "festival-as-non-profit," gradually establishing a domestic network of independent film festivals. This rhizomatic mode of development echoes Marijke De Valck's analysis of the international film festival circuit. It refers in particular to the theory of the rhizome, developed by Gilles Deleuze and Felix Guattari, to show that the creation of new festivals was the result of the deterritorialization of the existing network. ${ }^{\text {xxxiv }}$ I therefore consider the proliferation of Chinese independent film festivals to be an extension of the international festival network.

As this domestic network grew, however, the new elements gradually transformed: they became both identical to and yet different from the existing ones. In the case of BIFF, this transformation was generated by a process of negotiation between the government and the festival that resulted in a retreat into private space and an affirmation of the political commitment of the festival's organizers. Following this process of negotiation, the term "independent," originally associated with a personal mode of expression, increasingly took on a sense of political activism. The term "festival," originally associated with the desire for greater visibility and public recognition, came to mean private gatherings within a small community. Although BIFF now bears little resemblance to a western film festival, either in its configuration or its objectives, the organizers still maintain the English word "festival," and continue to claim this idea for their event, as if it validates their existence and value vis- 
à-vis the outside world.

These developments suggest how translation can be analyzed as an evolving process that contributes to the very fabric of culture and society: as the concept of "festival" travels round the world, it transforms national and international cultural landscapes. This broader, metaphorical understanding of translation appeared in the 1980 and 1990s, contemporaneous with the emergence of cultural and postcolonial studies. These disciplines considered culture to be a dynamic concept generated via translation, particularly in contexts of intense geographical mobility, or in postcolonial nations where subcultures were subordinate to the authority of hegemonic cultures. These theories have been criticized for their failure to overcome colonial paradigms and their neglect of historical empiricism. However, they still enhance our understanding of the consequences of introducing a global model of cultural organization (the festival-as-non-profit) into contemporary China.

My interest here is particularly in Homi Bhabha's notion of "third space," developed in his book The Location of Culture. Kate Sturge explains this concept as follows:

Translation is not an interchange between discourse wholes but a process of mixing and mutual contamination, and not a movement from "source" to "target" but located in a "third space" beyond both, where conflicts arising from cultural difference and the different social discourses involved in those conflicts are negotiated. ${ }^{\mathrm{xxxv}}$

In other words, translation processes generate hybrid spaces where binary divisions such as source-target, and more generally, all antagonisms around which modern societies are built, no longer apply. These spaces are politically subversive in nature, and contribute to the constant re-formation of boundaried cultural entities (generally national in scale) through frictions and negotiations.

With reference to the Chinese independent film scene, this suggests that the introduction of a global model of cultural organization allowed the creation of hybrid spaces (independent film festivals), which stimulated the rise of new forms of cultural practice and social interaction (exchanges based around common interests and experiences) amongst filmmakers and festival-goers. These hybrid spaces were also counter-hegemonic: the view that cultural events should be organized independently of government control challenged the power of the Chinese party-state. In response to this challenge, the government tried to 
reduce the visibility of the festivals and then stop them indefinitely. The response of BIFF's management team to these pressures modified the nature of the private space at the $\mathrm{Li}$ Xianting Foundation: this space could not operate as a public sphere because it was not accessible to the general public and remained effectively invisible to Chinese society at large. However, the foundation demonstrated a capacity to extend its influence beyond its spatial limits, through English-language media coverage. This private space thus became politically sensitive for the government which, in turn, had to adapt to the potential threat posed by the festival's new strategies.

I believe that, over the years, the authorities have responded to these developments by setting up an increasingly systematic model of intervention vis-à-vis independent film festivals. Before an event, government representatives send threats to the organizers and prohibit access to screening venues. If the organizers still manage to hold screenings elsewhere, police and local officials will go to the opening ceremony and cut the electricity, dispersing the participants and talking to the organizers. After this interruption, the festival sometimes continues in small groups under the supervision of local officials, who oblige the organizers to announce an early closure of the event. In this way, the authorities have adapted their modus operandi to the independent festivals, and have continuously re-negotiated the limits of their interference with these collective activities. In reaction, festivals have had to update their strategies: Li Xianting's argument that they cannot prevent him from organizing private screenings at home was accepted in 2011, but was no longer acceptable in the years that followed. This process of mutual adaptation calls into question the division between public space, where public opinion is controlled and guided by the party-state, and private space, where people have no visibility or outside influence. In this sense, the private space of the Li Xianting Foundation could be understood, metaphorically, as a third space. It constitutes an interstitial and transgressive place where the boundaries between the antagonistic categories around which Chinese contemporary society is built-government versus independent, public versus private, national versus transnational—become porous and blurred.

\section{Conclusion}

This chapter has focused on the translation of the "festival-as-non-profit" model into China using BIFF as a case study. As previously noted, the lack of a truly independent third 
sector in the PRC shaped the way in which this model was appropriated. With no clearly defined public space independent of government surveillance, BIFF evolved not purely an outward facing event designed to raise the profile of independent cinema in China, but also as a space focused on sustaining the independent film community. I have suggested it was a liminal space, hybrid in nature, where old relationships and identities could be dissolved and new ones constructed.

However, as Béatrice Collignon has pointed out, this interstitial space is ephemeral in nature, since it is directly related to the specific context in which it is situated. ${ }^{\mathrm{xx} x \mathrm{i}}$ In the case of Chinese independent film festivals, this space was created during a period of relative tolerance on the part of the government. At the beginning of their mandate in 2003, the former Chinese President and Premier Hu Jintao and Wen Jiabao made it a point of honor of listening to the grievances of citizens over issues of local governance. But the exponential increase of petitioners seeking audiences in the capital in the run up to the 2008 Olympics encouraged the government to rein in various forms of popular expression. ${ }^{\text {xxxvii }}$ This political clamp down has continued since 2013; the arrival of the new leadership team, comprised of $\mathrm{Xi}$ Jinping and Li Keqiang, led to the cancellation of most independent film festivals.

In reaction to their stigmatization by the government, BIFF's organizers asserted more firmly than ever before that they were engaged in a fight against the hegemony of dominant, state-controlled culture, drawing a distinction between the government in all its forms on the one hand, and independent filmmakers and organizers on the other hand. They locked themselves into a fixed identity, reproducing oppositional relationships that had previously been dissipated. In other words, the festival organizers crystallized the movement generated by the creation of independent film festivals, which had enabled individuals to rethink their relationship with social, cultural, and political activities. This demonstrates that these festivals are composed of contradictory flows of both movement and crystallization, and that movement was mainly generated during the period of political relaxation in the mid-2000s. I therefore argue that the introduction into China of global models such as the "festival-as-non-profit" can form hybrid spaces that modify the sociocultural landscape, as long as they do not challenge the authority of the party-state. To conclude on a positive note, however, in 2014 CIFF was held in Nanjing despite the closure of all the other independent film festivals. Discussed by Sabrina Yu and Lydia Wu in their chapter in this collection, CIFF's survival (so far) gives some hope that new hybrid and transgressive spaces will emerge in China in the 
near future.

${ }^{\mathrm{i}}$ Zhen Zhang, "Introduction: Bearing Witness. Chinese Urban Cinema in the Era of 'Transformation',' in The Urban Generation: Chinese Cinema and Society at the Turn of the Twenty-first Century, ed. Zhen Zhang (Durham: Duke University Press, 2007), 36-40.

ii Ying Liang, interview with the author, July 29, 2011, Songzhuang.

iii Ragan Rhyne, "Film Festivals Circuit and Stakeholders," in Film Festival Yearbook 1: The Festival Circuit, ed. Dina Iordanova and Ragan Rhyne (St Andrews: St Andrews Film Studies, 2009), 9-22.

${ }^{\text {iv }}$ Ros Derrett, "Festivals and Regional Destinations: How Festivals Demonstrate a Sense of Community and Place," Rural Society 13, no. 1 (2009): 35-53.

v Chris Berry, "When is a Film Festival not a Festival? The $6^{\text {th }}$ China Independent Film Festival," Senses of Cinema, December, 2009, accessed May 17, 2010, http://www.sensesofcinema.com/2009/festival-reports/when-is-a-film-festival-not-a-festivalthe-6th-china-independent-film-festival/.

vi Walter Benjamin, "The Task of the Translator: An Introduction to the Translation of Baudelaire's Tableaux Parisiens," trans. Harry Zohn, in The Translation Studies Reader, ed. Lawrence Venuti (New York, London: Routledge, 2010), 77.

vii In this chapter, the terms "government" and "authorities" are used interchangeably. They designate police officers and government officials of different administrative levels. This imprecision is due to the fact that I could not always precisely identify the various representatives of the authorities during my fieldwork.

viii Mohammed Kerrou, "Introduction," in Public et privé en islam: Espaces, autorités et libertés, ed. Mohammed Kerrou (Paris: Maisonneuve et Larose, 2002), 26.

ix Jürgen Habermas, L'espace public: Archéologie de la publicité comme dimension de la 
société bourgeoise, trans. Marc de Launay (Paris: Payot, 1997), 25-41.

x Jonathan Unger, "Introduction: Chinese Associations, Civil Society, and State Corporatism: Disputed Terrain," in Associations and the Chinese State: Contested Spaces, ed. Jonathan Unger (Armonk: M.E. Sharpe, 2007), 1-13.

${ }^{x i}$ Li Xianting, "We Just Want to Make the Films We Like-The 6th Beijing Independent Film Festival," in Diliujie Beijing duli dianyingzhan [The sixth Beijing independent film festival catalogue] (Songzhuang: BIFF, 2011), n.p. All section titles and quotations from BIFF catalogues in this chapter are from the original catalogue translations into English, unless otherwise indicated.

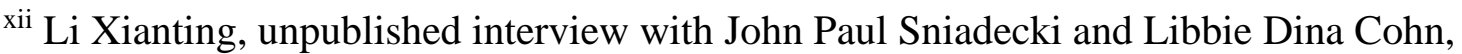
August 24, 2012, Songzhuang.

xiii Zhang Qi, interview with the author, August 27, 2011, Songzhuang.

${ }^{\text {xiv }} \mathrm{Li}$, interview.

${ }^{x v}$ The National Congress is the Chinese Communist Party's highest-level decision-making body. The Congress has taken place every five years since 1921, and comprises 2270 delegates elected from the provincial and municipal governments and from the army. Delegates elect the party leadership and ratify new policies.

${ }^{x v i}$ Dina Iordanova, "The Film Festival Circuit," in Film Festival Yearbook 1: The Festival Circuit, ed. Dina Iordanova and Ragan Rhyne (St Andrews: St Andrews Film Studies, 2009), 23-39.

${ }^{\text {xvii }} \mathrm{Li}$, interview.

xviii Zhu Rikun, interview with the author, email, April 30, 2011.

${ }^{x i x}$ For more on this topic, see Mette Halskov Hansen and Rune Svarverud, ed., iChina: The Rise of Individual in Modern Chinese Society (Copenhagen: Nordic Institute of Asian Studies, 2010). 
${ }^{\mathrm{xx}}$ Zhu, interview.

${ }^{\mathrm{xxi}}$ Howard Becker, Outsiders: Etudes de la sociologie de la deviance, trans. Jean-Pierre

Briand and Jean-Michel Chapoulie (Paris: M.A. Métaillé, 1985), 120-24.

xxii Li Xianting, "Combining Efforts to Build 'Small Environments',” trans. Ying Qiang, in

Dijiujie Beijing duli yingxiangzhan [The ninth Beijing independent film festival

catalogue] (my translation) (Songzhuang: BIFF, 2012), n.p.

xxiii $\mathrm{Li}$, interview.

xxiv Ibid.

${ }^{x x v}$ Zhu Rikun, “Preface,” trans. John Paul Sniadecki, in Disijie Beijing duli dianyingzhan

[The fourth Beijing independent film festival catalogue] (my translation) (Songzhuang: BIFF, 2009), n.p.

xxvi Zhu Rikun, "BIFF Foreword: What Kind of Festival to Hold?," trans. John Paul

Sniadecki, in Diwujie Beijing duli dianyingzhan [The fifth Beijing independent film festival

catalogue] (my translation) (Songzhuang: BIFF, 2010), n.p.

xxvii Li, "We Just Want to Make the Films We Like,” n.p.

xxviii Li Xianting, "Preface," in Dishijie Beijing duli yingxiangzhan [The tenth Beijing independent film festival catalogue] (my translation) (Songzhuang: BIFF, 2013), n.p.

xxix Václav Havel, "The Power of the Powerless," in The Power of the Powerless: Citizens Against the State in Central-Eastern Europe, ed. John Keane (London: Hutchinson, 1985), 63.

xxx Jonathan Benney, Defending Rights in Contemporary China (London, New York: Routledge, 2013), 142-143.

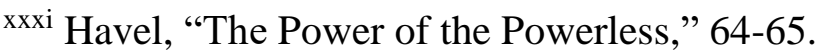

xxxii Quoted in Louise Watt, "China Acts to Chill Interest in Independent Films,” Associated Press, August 30, 2013, accessed March 17, 2014, http://bigstory.ap.org/article/china-acts- 
chill-interest-independent-films.

xxxiii Daniel Dayan, "Looking for Sundance: The Social Construction of a Film Festival," in Ib Bondebjerg, ed. Moving Images, Culture, and the Mind (Luton: University of Luton Press, 2000), 43-52.

xxxiv Marijke de Valck, Film Festivals: From European Geopolitics to Global Cinephilia (Amsterdam: Amsterdam University Press, 2007), 31.

${ }^{\text {xxxv }}$ Kate Sturge, "Cultural Translation," in Routledge Encyclopedia of Translation Studies, ed. Mona Baker and Gabriela Saldahna (London, New York: Routledge, 2011), 69.

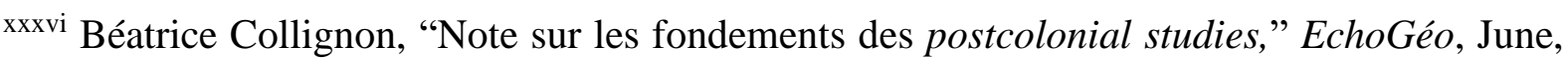
2007, accessed April 30, 2015, http://echogeo.revues.org/2089.

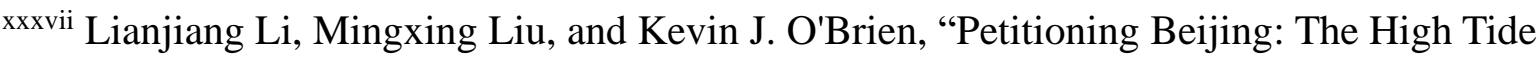
of 2003-2006," The China Quarterly 210 (2012): 313-34. 